\title{
Proportion and Factors that Associate with Incidence of Hepatotoxicity in Rheumatoid Arthritis Patients Treated with Methotrexate in RSCM Year 2013-2015
}

\author{
Leonardo Satria ${ }^{1}, Z_{1}$ ke Maritska2 ${ }^{*}$, Nita Parisa ${ }^{3}$ \\ ${ }^{1}$ General Medicine, Faculty of Medicine, University of Indonesia \\ ${ }^{2}$ Rheumatology Division, Department of Internal Medicine, Faculty of Medicine University of Indonesia
}

\section{A R T I C L E I N F O}

\section{Keywords:}

Rheumatoid Arthritis

Methotrexate

Hepatotoxicity

\section{Corresponding author:}

Rahma Anindya Prathitasari

\section{E-mail address:}

r.anindya28@gmail.com

All authors have reviewed and approved the final version of the manuscript.

https://doi.org/10.37275/IJR.v10i1.1

\begin{abstract}
A B S T R A C T
Background Rheumatoid arhtirtis (RA) is a chronic autoimmune disease that mainly attacks joints. It may causes joint deformities which leads to lower quality of life of RA patients. RA is treated with metothrexate (MTX) which inhibiting disease progression. MTX is known for its hepatotoxicity side effect, which is described by an elevation of aspartate aminotransferase (AST) and/or alanine aminotransferase (ALT) beyond the upper normal limit. Factors that may enhance hepatotoxicity are gender, age, cummulative dose of MTX, and duration therapy of MTX. Prevalence of hepatotoxicity caused by MTX therapy in RA patients in Indonesia is still unknown. The objective of this research is to know the proportion of hepatotoxicity and its associations with the factors that may enhance hepatotoxicity caused by MTX therapy in RA patients in RSCM. Method Data about gender, age, cummulative dose and duration therapy of MTX are obtained from 115 RA patients' medical records. Result Proportion of hepatotoxicity in RA patients treated with MTX in RSCM is $42.60 \%$. Gender, age, cummulative dose and duration therapy of MTX do not significantly enhance hepatotoxicity $(p>0.05)$. Conclusion In conclusion gender, age, cummulative dose and duration therapy of MTX do not have association with hepatotoxicity in RA patients treated with MTX.
\end{abstract}

\section{Introduction}

Rheumatoid arthritis (RA) is an inflammatory disease which has large impacts on daily activities of its sufferers. Inflammation manifests as pain that causes joint immobility. American College of Rheumatology and European Leauge Against Rheumatism (ACR-EULAR) created a tool to help diagnose RA in 2010. After the diagnosis is set, patient would be treated with Disease Modifying Anti Rheumatic Drugs (DMRADs). The target of DMARDs therapy is inhibiting joint erosion and causing remission. Based on ACR guideline on management of
RA in year 2015, the first line therapy for is methotrexate (MTX). MTX works by supressing cytokine release and lymphocyte proliferation that contributes to the progressivity of RA.1-7

Methotrexate is known to trigger liver dysfunction as side effect. Liver function is evaluated based on alanine aminotransferase (ALT) and/or aspartate aminotransferase (AST) serum titer. Elevation of liver enzyme above the upper limit indicates liver dysfunction. Based on study in India on 30 patients who were treated with MTX for 3 months, there was 
$25 \%$ elevation of AST above normal range. 8 Study in Israel on 119 patients who were treated with MTX showed $43 \%$ of RA patients have abnormal liver enzyme titer. ${ }^{9}$ Study in Iran on 286 patients who were treated with MTX found that $23.7 \%$ of patients have experienced liver dysfunction. ${ }^{10}$ Based on the previous studies, factors that suspected association with liver dysfuction are gender, age, MTX cumulative dose, and MTX duration therapy. ${ }^{8-11}$

There is not any study about proportion of liver dysfuction on RA patients who are treated with MTX in Indonesia. The purpose of this study is to have the proportion of liver dysfunction in patients who are treated with MTX, and to analyze the association between age, gender, MTX cumulative dose, MTX therapy duration with liver dysfunction incidence, so that clinicians will be more aware with MTX use in patients.

\section{Research Methods}

This study is a descriptive-analytic study with cross-sectional method. From the sample population, AST and ALT lab results, age, gender, MTX cumulative dose, and MTX duration therapy were obtained. The study was conducted in RSUPN Dr Cipto Mangunkusumo (RSCM) and RSCM Kencana, Jakarta for 11 months, from January to November 2016.

Data were obtained from patients' medical records unit RSCM and RSCM Kencana, which meet inclusion criteria and opposite of exclusion criteria. The inclusion criterias are patients who fulfill diagnosis criteria of based on ACR/EULAR 2010, received MTX therapy for minimum period of one month, and patients of RSCM and RSCM Kencana. The exclusion criterias are patients who have other comorbidities that can cause liver dysfunction.

Data were processed by SPSS software and analyzed with inferential statistic. Gender and liver function variables were analyzed with Fisher test. Age, MTX cumulative dose, and MTX therapy duration variables undergone sample normality test with Kolmogorov Smirnov test. If the data distribution were normal, unpaired T- test between age, MTX cumulative dose, and MTX duration therapy and liver function would be conducted. If not normal, the Mann-Whitney test would be done. From the Mann-Whitney test, p value showed data significance.

\section{Results}

From 115 samples who were obtained, all the samples were given MTX with minimum dosage of 7.5 mg each week for minimum duration of one month. Samples do not have any comorbidities that could result in liver dysfunction. Samples demographic datas are shown in Table $\mathbf{1}$

\section{Association between gender and liver dysfunction}

There is no significant difference between proportion of men and women ( $>0.05)$ in group with liver dysfunction and without.

\section{Association between age and liver dysfunction}

There is no significant association between age and liver dysfunction incidences ( $p>0.05)$.

\section{Association between MTX cumulative dose and liver} dysfunction

There is no significant association between MTX cumulative dose and liver dysfunction incidences $(\mathrm{p}>0.05)$.

Association between MTX duration therapy and liver dysfunction

There is no significant association between MTX duration therapy and liver dysfunction incidences $(\mathrm{p}>0.05)$. 
Table 1. Samples Demographic Data

\begin{tabular}{c}
\hline Variable \\
\hline Gender, frequency (\%) \\
Men \\
Women
\end{tabular}

Age (year)

MTX cumulative dose (mg)

MTX duration therapy (week)

AST titer, frequency (\%)

Normal

1-2 times above normal

$>2$ times above normal

ALT titer, frequency (\%)

Normal

1-2 times above normal

$>2$ times above normal

Liver dysfunction, frequency (\%)
Result

$9(7.83 \%)$

$106(92.17 \%)$

$53.55(19.98-84.53) *$

$480.00(25.00-3967.50) *$

$44.00(4-226)^{*}$

$73(63.48 \%)$

$36(31.30 \%)$

$6(5.22 \%)$

${ }^{*}$ :not normally distributed data, data presented in median (range)

Table 2. Association between gender and liver dysfunction

\begin{tabular}{lccc}
\hline \multicolumn{1}{c}{ Variables } & Normal LFT & Disturbed LFT & P value \\
\hline Women & $63(95.5)$ & $43(87.8)$ & 0.167 \\
Men & $3(4.5)$ & $6(12.2)$ &
\end{tabular}

LFT: Liver Function Test

Table 3. Association between age and liver dysfunction

\begin{tabular}{llcc}
\hline & Liver function & Result & P score \\
\hline \multirow{2}{*}{ Age } & Normal & $52.85(19.98-84.53)^{*}$ & $0.46-0.23$ \\
& Disturbed & $54.78(23.56-72.75)^{*}$ & \\
\hline \multirow{2}{*}{$*$ not normally distributed data, data presented in median (range) }
\end{tabular}

*:not normally distributed data, data presented in median (range)

Table 4. Association between MTX cumulative dose and liver dysfunction

\begin{tabular}{lccc}
\hline & Liver function & Result & P score \\
\hline \multirow{2}{*}{ MTX cumulative dose } & Normal & $378.75(25.00-3337.50)^{*}$ & $0.23-0.115$ \\
& Disturbed & $495.00(50.00-3967.50)^{*}$ & \\
\hline
\end{tabular}

${ }^{*}$ :not normally distributed data, data presented in median (range) 
Table 5. Association between MTX duration and liver dysfunction

\begin{tabular}{|c|c|c|c|}
\hline & Liver function & Result & P score \\
\hline \multirow{2}{*}{$\begin{array}{c}\text { MTX } \\
\text { duration } \\
\text { therapy }\end{array}$} & Normal & $43(4-226)$ * & $0.519-0.259$ \\
\hline & Disturbed & $44(5-207)$ * & \\
\hline
\end{tabular}

\section{DISCUSSION}

Proportion of liver dysfuction in patients who are treated with MTX in RSCM and RSCM Kencana is $42.60 \%$. The proportion of liver dysfunction in this study is higher than study conducted by Sotoudenamesh et al which has proportion of liver dysfunction 23.7\%.11 However, proportion of liver dysfunction in this study is suitable with other studies which conducted by Ede et al which stated that proportion of liver dysfunction is $53 \%$ and Bath et al which stated proportion of liver dysfunction is 15-50\%. RA patients who are treated with chronic MTX experienced elevations in ALT and/or AST above the normal upper limit. About $5 \%$ of which experienced elevation until 2 times the normal range. ${ }^{12}$ This study result has 5.22\% samples who experienced AST and/or ALT 2 times normal range. In the literature review by Conway et al liver dysfunction incidence is higher than liver dysfunction incidence in this study, AST and/or ALT elevations above normal upper limit and those who elevated above two times normal range is $48.9 \%$ and $16.8 \%$ respectively. ${ }^{13}$

Variations of liver dysfunction proportion in other studies might be caused different definitions of liver dysfunction. In this study, liver dysfunction is described as ALT and or AST abnormal result while treated with MTX. Sotoudenamesh et al described liver dysfunction as two abnormal ALT and AST results in interval of 2 weeks. ${ }^{10}$ Kremer et al described liver dysfunction based on liver hystology. The proportion differences also can be caused by different sample characteristics (ethnic and genetic variation). 10

The time of laboratory test from last administration of MTX can also affect the liver enzyme titer. If the lab test were conducted after MTX administration, liver enzyme titer would be higher. ${ }^{14}$

Folic acid supplementation is known to decrease the frequency of liver enzyme elevation. ${ }^{15}$ MTX hepatotoxicity mechanism is still unknown but allegedly result from the same mechanism of this drug mechanism of action. MTX causes inhibition of DNA and RNA synthesis in liver which result in damage and degeneration of liver cell. If the patients were given folic acid, DNA and RNA synthesis are not disturbed.14, 16

Epidemiologically, RA incidence is two to three times higher in women than in men. The reason behind it is still unknown but thought to be genetic factor that $\mathrm{X}$ linked and estrogen factor. ${ }^{14}$ Studies by Amital et al and Parvin et al found women are more fragile to liver enzyme elevations. ${ }^{8,9}$ Hoekstra et al study shown women are more prone to MTX treatment discontinuation. ${ }^{15}$ However, in this study, gender and liver dysfunctions do not have any significant association. This study result is suitable to Sotoudenamesh et al study. 10

Age median in this study is 52.8 years $(19.98,84.53)$ in group without liver dysfunction and 54.78 years $(23.56$, 72.75) in group with liver dysfuncton. There is no significant association between age and liver dysfunction incidence. This result is suitable to study by Sotoudenamesh et al, Hoekstra, and McKendry which also did not find any association between age and liver dysfunction in RA patients who are treated with MTX.10,15

Most of MTX would be eleminated from the body through kidney, meanwhile kidney function would degenerate as the age increased. If MTX titer in body high, the risk of hepatotoxicity is even higher. Therefore age is considered as risk factor for MTX hepatotoxicity. However, some studies showed different result from the theory. Study by Felson in 496 RA patients and Bologna in 469 RA patients did not find association between age, kidney 
function, and elevation of liver enzymes. ${ }^{15}$ In this study, the researchers do not know about patients' kidney function.

In this study, there is no significant comparison between MTX cumulative dose in group with liver dysfunction and without liver dysfunction. MTX cumulative dose median in group with liver dysfunction is $495 \mathrm{mg}$, meanwhile in group without liver dysfunction is $378.75 \mathrm{mg}$. Even though there is no significant difference, MTX cumulative dose median in group with liver dysfunction is higher than cumulative dose median in group without liver dysfunction. In this study, MTX cumulative dose is lower than in other previous studies.

The result of this study is not suitable with studies which conducted by Sakthiswary et al and Sotoudenamesh et al which were acquired significant difference of MTX cumulative dose in group with liver dysfunction and without liver dysfunction. 10,17 According to the theory, incidences of hepatotoxicity are associated with increasing MTX dose. However, in various studies by West et al and Lanse et al also did not find any increasing risk of hepatotoxicity with increasing of MTX dose. ${ }^{18}$

Study by Bath et al showed significant association between MTX cumulative dose and liver dysfunction in RA patients treated with MTX once a day or every two days. However, in RA patients treated with MTX once a week, there is a weak association between MTX cumulative dose and hepatotoxicity. Liver dysfunction incidence is more associated with time interval between two MTX administrations than MTX cumulative dose. When the drug is administrated in one week interval, MTX titer in the body is not high enough to cause hepatotoxicity. ${ }^{18}$ In this study, RA patients are treated with MTX weekly. No significant difference in MTX cumulative dose and liver dysfunction could be caused by time interval between two administrations. Studies by Parvin et al and Rau et al stated that liver enzymes elevations were transient and will normalized after decreasing of MTX dose, giving of folic acid, or even without changes in MTX dose. 8,19

No significant difference between MTX cumulative dose and liver dysfunction incidence could be caused by MTX cumulative dose which are lower in this study than other previous studies. In this study, MTX cumulative dose median in group without liver dysfunction is $378.75 \mathrm{mg}$ and group with liver dysfunction is $495 \mathrm{mg}$. Meanwhile in Sotoudenamesh et al, MTX cumulative dose mean in group without liver dysfuncton is $1707.3 \mathrm{mg}$ with $45.2 \%$ of them were given MTX more than $1.5 \mathrm{~g} .{ }^{10}$ In the literature review by Kremer, hepatotoxicity incidence in RA patients who are treated with MTX is low. Hepatotoxicity incidence is higher in cancer patients who are treated with higher MTX dose. 8

The median MTX duration therapy in group with liver dysfunction is 43 weeks and without liver dysfunction is 44 weeks. In this study, there is no significant association between MTX duration therapy and liver dysfunction. This result could be caused by short MTX duration therapy. Sotoudenamesh et al studies found significant association between MTX duration therapy and liver dysfunction. In Sotoudenamesh et al study, MTX duration therapy in group with liver dysfunction reached 59.6 \pm 42.3 months. ${ }^{10}$

MTX duration therapy is associated with MTX cumulative dose. However, hepatotoxicity is more associated with time interval between two drug administrations than the MTX duration therapy. In study by Rau et al, hepatotoxicity is not a significant side effect in weekly low dose MTX therapy. Patients are more tolerant with weekly MTX therapy than daily MTX therapy.

\section{CONCLUSION}

Based on this study, it could be concluded proportion of RA patients who have liver dysfunction caused by MTX therapy in RSCM is $42.70 \%$. Gender, age, MTX cumulative dose, and MTX duration therapy do not have any statistically significant association with liver dysfunction.

\section{REFERENCES}

1. O'dell JR. Rheumatoid arthritis, In: Goldman-Cecil Medicine. Ed 25. Philadelphia: Elsevier Saunders; 2016. p1754-62

2. Ferri FF. Ferri's Clinical Advisor 2016. Philadelphia: Elsevier; 2016. p1084-6

3. Singh JA, Saag KG, Bridges Jr. SL, Vaysbrot E, Bannuru RR, Sullivan MC, et al. 2015 American college guideline for the treatment of rheumatoid arthritis. Arthritis Res Ther. 2016 Jan; 68: 4-8 
4. IRA. Rekomendasi Diagnosis dan Pengelolaan Artritis Reumatoid. Perhimpunan Reumatologi Indonesia. 2014:4-22

5. O'Dell JR. Treatment of rheumatoid arthritis, In: Firestein FS, Budd RC, Gabriel SE, McInnes IB, O’Dell JR. Kelly's Textbook of Rheumatology. Ed 9. Philadelphia: Elsevier Saunders; 2013. p1137-60

6. Aletaha D, Neogi T, Silman AJ, Funovits J, Felson DT, Bingham CO, et al. 2010 Rheumatoid arthritis classification criteria. Arthritis \& Rheumatism. 2010 Sept 9; 62(9); 2572-4.

7. Cronstein BN. Low-dose methotrexate: A mainstay in treatment of rheumatoid arthritis. Pharmacol Rev. 2005;57(2): 163-70

8. Parvin MS, Rashid MU, Ekram ARMS, Begum HA. Early hepatotoxicity of methotrexate in rheumatoid arthritis. TAJ. 2008 Dec; 21(2): 147-51

9. Amital H, Arnson Y, Chodick G, Shalev V. Hepatotoxicity rates do not differ in patients with rheumatoid arthritis and psoriasis treated with methotrexate. Rheumatology Advance Access. 2009 July;48: 1107-10

10. Sotoudehmanesh R, Anvari B, Akhlaghi M, Shahraeeni S, Kolahdoozan S. Methotrexate hepatotoxicity in patients with rheumatoid arthritis. Middle East Journal of Digestive Diseases. 2010 Sept; 2(2): 104-8

11. Neogi T, Felson D, McMahon S, Koltzenburg M, MA T, Turk DC. Osteoarthritis and rheumatoid arthritis, In: Wall \& Melzack's Textbook of Pain. Ed 6. Philadelphia: Elsevier Saunders; 2013. p653-7

12. Bath RK, Brar NK, Forouhar FA, Wu GY. A review of methotrexate-associated hepatotoxicity. 2014; 15(10): 517 - 524. doi: 10.1111/1751-2980.12184

13. Conway R, Low C, Coughlan RJ, O'Donnell MJ, Carey JJ. Risk of liver injury among methotrexate users - a meta-analysis of randomized controlled trials. Seminars in Arthritis and Rheumatism. 2015;05(003): $2-16$

14. Hoekstra M, A E van Ede, C J Haagsma, M A F J van de Laar, T W J Huizinga, M W M Kruijsen, R F J M Laan. Factors associated with toxicity, final dose, and efficacy of methotrexate in patients with rheumatoid arthritis. Ann Rheum Dis. 2003;62:423-6

15. Dehestani V, Shariati-Sarabi Z, Mohitt S, Akhlaghi S. Liver Toxicity in Rheumatoid Arthritis Patients Treated with Methotrexate. Asia Pac J Med Toxicol. 2015;4:102-5

16. Sakhtiswary R, Chan GYL, Koh ET, Leong KP, Thong BYH. Methotrexate-associated nonalcoholic fatty liver disease with transaminitis in rheumatoid arthritis. TSWJ. 2014(823763): 1-4

17. Bath RK, Brar NK, Forouhar FA, Wu GY. A review of methotrexate-associated hepatotoxicity. 2014; 15(10): 517 - 524. doi: 10.1111/1751-2980.12184
18. Rau R, Herborn G. Benefit and risk of methotrexate treatment in rheumatoid arthritis. Clin Exp Rheumatol. 2004;22(35):83-94 